\title{
An empirical analysis on the adoption of electronic banking in the financial institutes using structural, behavioral and contextual factors
}

\author{
Ali Akbar Ahmadi ${ }^{\mathbf{a}}$ and Mahdi Afrouzi ${ }^{\mathbf{b}^{*}}$
}

${ }^{a}$ Associate Professor, university Payam-e-noor, Tehran, Iran

${ }^{b}$ MBA student of Master Degree, university Payam-e-noor, Iran

\begin{tabular}{l}
\hline A R T I C L E I N F O \\
\hline Article history: \\
Received December 25, 2011 \\
Received in Revised form \\
March, 25, 2012 \\
Accepted 24 April 2012 \\
Available online \\
April 30 2012 \\
\hline Keywords: \\
Organizational factors \\
Structural factors \\
E-commerce \\
Behavior factors
\end{tabular}

A B S T R A C T

\begin{abstract}
This research examines contextual, structural and organizational factors, which can facilitate or slow down adoption of innovation in Electronic Banking in the financial Institutions. Threedimensional model co-structure, co-behavioral, contextual (3C) is used in this research. This schema is a logical model in the categories of models and many of concepts, events and organizational phenomena can be examined. Structural factors including type of the organization of institution, work distribution, preparing mobilization of resources and equipment and risk of decision-making sophistication influence on adoption of Electronic Banking. There are four contextual factors, which contribute in adoption of Electronic Banking including goals, strategies, culture and common norms. The five Behavioral Factors, which affect on electronic banking are connections and relations, skills and personal characters of employees, education, job satisfaction and banking work process. By studying the mentioned factors, we have realized that contextual factors plays important role on adoption of electronic Banking by employee and the behavioral and structural factors have minor impacts. The mentioned proposals are methods, which facilitate the adoption of electronic banking in the country.
\end{abstract}

\section{Introduction}

A decade after the introduction of the first commercial Internet sites, e-commerce is still captivating both university researchers, as well as business communities (Bergeron, 2001; Ngai \& Walt, 2002; Cyr et al., 2005). A number of surveys show that approximately $97 \%$ of consumers who make on-line transactions will continue adopting this type of behavior, with a majority claiming that they intend to increase their number of transactions over the past few months, significantly (Ernst \& Young, 2001). In general, consumers appear to be satisfied with e-commerce as an efficient, fast, and cheaper way of conducting business, and their online purchases are growing, steadily.

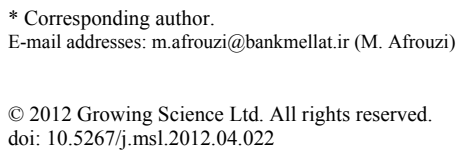


Among the industries influenced by e-commerce, the financial institutions are influenced the most by the technological revolution. The financial industry is based on the sharing of information, which itself relies heavily on information and communication technology (ICT) to acquire, analyze and deliver data to all relevant users. Financial institutions innovate continuously and update their marketing strategies to closely meet the desires and demands of their customers in a safe and confidential environment. These institutions must, on the one hand, equip themselves with cutting edge technologies to adapt, and, on the other hand, bring forward plans for a relationship-oriented marketing strategy. The end results will be the establishment of a culture, which prioritizes the customer, generates a climate of trust, and promotes increased knowledge and customer loyalty (Perrien et al., 1993; Ricard \& Perrien, 1999). ICT helps the financial organization improve the efficiency of their business processes and to improve their competitive positions (Rust \& Kannan, 2002). Therefore, in an era where different media such as TV or Satellite TV complement and overlap one another, the physical location of the bank is no longer considered to be critical for the customer. The customer wants more flexibility without paying more, and his/her demands includes different items such as online transactions wherever, whenever, and whichever way he/she wants. Hence, the development of the concept of electronic financial services is commonly known as "E-banking". This umbrella term embodies different services, such as common automatic teller machine (ATM) services, telephone banking, direct deposit, automatic bill payment (A'BP), the use of debit cards, Internet banking and computer banking (PC banking), etc. (Kolodinsky et al., 2004; Hernandez \& Mazzon, 2006). The use of E-banking technologies has grown rapidly in industrial markets like the USA (ABA Banking Journal, 2001).

The organizational consequences of the introduction of ICT, specifically E-banking, can initially take the form of strategic changes to management processes, the reorganization of the management network and even the reformulation of the company's purposes and business portfolio (Venkatraman, 1995). According to Badoc et al. (1994), banks must include e-banking into their processes to develop new activities and to approach new markets, more specifically, those of virtual financial services. E-banking seems a disruptive technology, which does not support current bank-based practices (Walsh et al., 2002). E-banking can also be considered as a disruptive innovation since it generates service and/or physical products with different performance attributes, which may not be valued by existing customers (Ibid, 2002). This is in agreement with Christensen \& Raynor (2003) who claimed that disruptive technologies do not necessarily need to be radically new from a technological point of view, but that it could contain superior "performance trajectories" along critical dimensions where customers value. However, the adoption of an innovation within an organization in general or, more specifically, that of "E-banking" within financial institutions, is not always an easy task. Although some factors will speed it up, many others can slow it down.

The purpose of this article is to analyze the contextual, structural and behavioral factors that can speed up or, conversely, slow down the Implementation of E-banking by financial institutions. The article proceeds as follows. The first section will review existing theories with respect to the adoption of E-banking. The second section proposes a theoretical model of the factors which influence the adoption of E-banking. Section 3 describes the methodology used for testing the above model. Section 4 presents the results of the statistical data analyze is, while the last section discusses the study's implications for research and practice and presents the study's limitations.

\section{Literature review}

\subsection{E-Banking Description}

Technology of banking was developed in 1980s based on a distance-based technology. Its advantage was accepted by customers who were looking for initiative process by which they could deal with their business affairs without being in the banks. These processes could be done by different 
approaches like PC Banking, Internet Banking, Co-Banking, TV Banking and phone Banking (Toufaily et al., 2009).

The first two mentioned approaches have been implemented more often due to their appropriateness in utilization. Evidently, e-Banking excels in proportion to Internet option. Internet is one of eBanking alternatives. Customers who are willing to adopt e-Banking approach are normally able to do their banking affairs in a shorter amount of time, with a lower expense, and without the need of being in the banks. This technology can be considered as a competitive advantage compared with others in a banking viewpoint. This advantage enables the banks to make new opportunities to develop and to promote the effectiveness and efficiency to attract more customers. The best advantage of e-banking is expense reduction and growing access and opportunities for attracting new customers and finally to meet their satisfaction. However, countries act differently towards this initial technology.

Basically, some pressures imposed by the technology, the law (for example; digital and its related rules) and customers' understanding, personal feeling toward e-banking and its performances make the process of adoption of e-banking in banks takes place slowly. Electronic banking offers benefits to both banks and customers. Pikkarainen et al. (2004) mentioned two fundamental reasons underlying online banking: Development and Penetration. First, that banks get significant cost savings in their operation through e-Banking services. It has been proved that online banking channel is the cheapest delivery channel for banking products once established. Second, that banks have reduced their branch networks and downsized the number of workforce, which has paved the way to self-service channels since quite many customers felt that branch banking took too much time and effort.

On the other hand, customers enjoy self-service, freedom from time and place constraints, and reduced stress of queuing in banking hall. Therefore, time and cost savings and freedom from place have been found the main reasons underlying online banking acceptance. It was indicated that electronic banking delivery services are the cheapest, the most profitable delivery channel for banking products (Pikkarainen et al., 2004). However, not all bank customers engage in using e-Banking services. There are multiple reasons for this. First, customers need to have access to the Internet in order to utilize some e-Banking facilities such as Internet and Mobile banking ones.

Furthermore, most new online users need to learn how to use the service first. Second, nonusers often complain online banking is incomprehensible, difficult to use and has no social dimension, i.e. the lack of face-to-face situation at branch (Karjaluoto 2001; Mattila et al., 2003). Third, customers are afraid of security issues (Ezeoha, 2005).

Bill Gates (2008) once said that «banking is essential, banks are not ». It means that the traditional bank branch is going to vanish in order to be replaced by electronic banking which continues to attract new users. For instance, according to TNS Canadian Facts, "six out of ten Canadians with the Internet the access to have signed up for online banking". The first and crucial threshold that is worthy to cross consists of defining this new resulting from the compatible union between technology and banking industry. In fact, the FFIEC (2003; p.2) published a booklet in which it advanced a very specific definition of e-banking: it is "the automated delivery of new and traditional banking products and services directly to customers through electronic, interactive communication channels." In other words, customers are allowed, henceforth, to enquire about their accounts, to access their funds and to carry out multiple transactions through networks and intelligent interactive devices such as Personal Computers (PC), Personal Digital Assistants (PDA), Automated Teller Machines (ATM), mobile phones, Minitel, Wireless Application Protocol (WAP), TV ... without surely forgetting the famous device called the internet which could lead ebanking to achieve its apogee since the number of surfers, in the world, has exceeded one billion at 
1672

the dawn of 2009, as it was declared by the "ComScore Institute".

\section{Adoption of New Technologies}

Several competing theoretical approaches have been used to investigate the determinants of individual acceptance and use of information technology (Venkatesh ctal.. 2003). One line of research focuses on the factors that predict the behavioral intention of the consumer (intention to adopt a new technology) or on the behaviour itself (actual adoption of new technology). The most important of these studies are centered on the Theory of Reasoned Action (TRA) (Fishbein \& Ajzen, 1975), on the Theory of Planned Behavior (TPB) (Ajzen. 1985). and on the Technology Acceptance Model (TAM) (Davis, 1989). Among the adoption determinants upon which these models are based can be found: beliefs, subjective norms, attitudes, perceived usefulness, perceived ease of use and perception of behavioral control.

A second line of research has considered adoption of new technologies from the perspective of the Innovation Diffusion Theory (Rogers, 1983). Rogers (1983) proposed a model of the adoption of innovations that included five product or service characteristics postulated to influence consumer acceptance of an innovation. These are defined as follows:

Relative advantage: This refers to the degree in which consumers perceive a new product or service as different form and better than its substitutes.

Trialability: Refers to the ability of consumers to experiment with a new innovation and evaluate its benefits. It is the extent to which consumers can try out the new technologies and products before purchasing (Kolodinsky et al., 2004).

Compatibility: This is the extent to which the innovation is perceived as being in line with the values, needs, beliefs and experiences of prospective adopters. In the case of E-banking, it means the degree to which a given technology fits in with the banking behavior of the institutions and their customers; specifically, the way in which they have historically managed their finances.

Complexity: Refers to the extent to which the innovation is perceived as difficult to understand and use. For consumers without previous computer experience, and for whom that e-banking is difficult to use, adoption of the innovation may be frustrated (Kolodinsky et al., 2004).

Observability: It is the extent to which an innovation is visible and communicable to consumers. In the case of E-banking, some channels are more observable than others.

These are collectively important factors for customers in their decisions to adopt E-banking (Sayar \& Wolfe, 2007). Several researchers have incorporated some of the dimensions of Rogers'model in empirical work that examined technological innovations (Raju, 1980; Dab-holkar. 1996; Daniel, 1999; Tan \& Teo, 2000 Lee et al., 2003). It should be pointed out that Rogers'(1983) theory was conceived for use by a decision making unit, a unit which could just as well be an individual consumer or an organization. From the perspective of the financial organizations, the results of the study on the drivers and inhibitors of the adoption of E-banking show that the decision by banks to adopt E-banking is driven mostly by "external factors'", such as the number of other banks adopting, competitive forces, consumer demand and technological availability (Bradley and Stewart. 2002). According to Sayar and Wolf (2007), the decision to adopt is mostly effected by new revenue potential, cost reduction, security and access through other distribution channels. The main inhibitors of E-banking were identified as PC ownership, authentification issues on the Internet and resistance to change. Mols (2001) conducted a survey among the managers of banks in Denmark, which shows that management support and future orientation are the most important factors driving the introduction of a new electronic distribution channel. For bank managers the efficiency and 
enhancement of customer services, through faster, easier and more reliable service and improvement of the competitive position (Aladwani, 2001) are considered as the main advantages of offering Ebanking services. Size and cost-effectiveness (Bughin. 2003) are also two critical factors for a bank's adoption decision.

\section{Definition of Various Types of E-Banking}

\subsection{Conceptual framework}

According to Rogers (1983), "An innovation is an idea, practice or object that is perceived as new by an individual or other unit of adoption". The adoption of E-banking by a financial institution, like any other innovation, isn't an easy process. Rather, it depends on many factors, some of them are organizational: others are related to structural factors of the innovation, and others arise from the strategy of the unit that adopts it.

The conceptual framework presented in figure I summarizes the variables that are retained and that will be used as the fundamental basis of our empirical study(3C model)(Mirzayi, 1997).

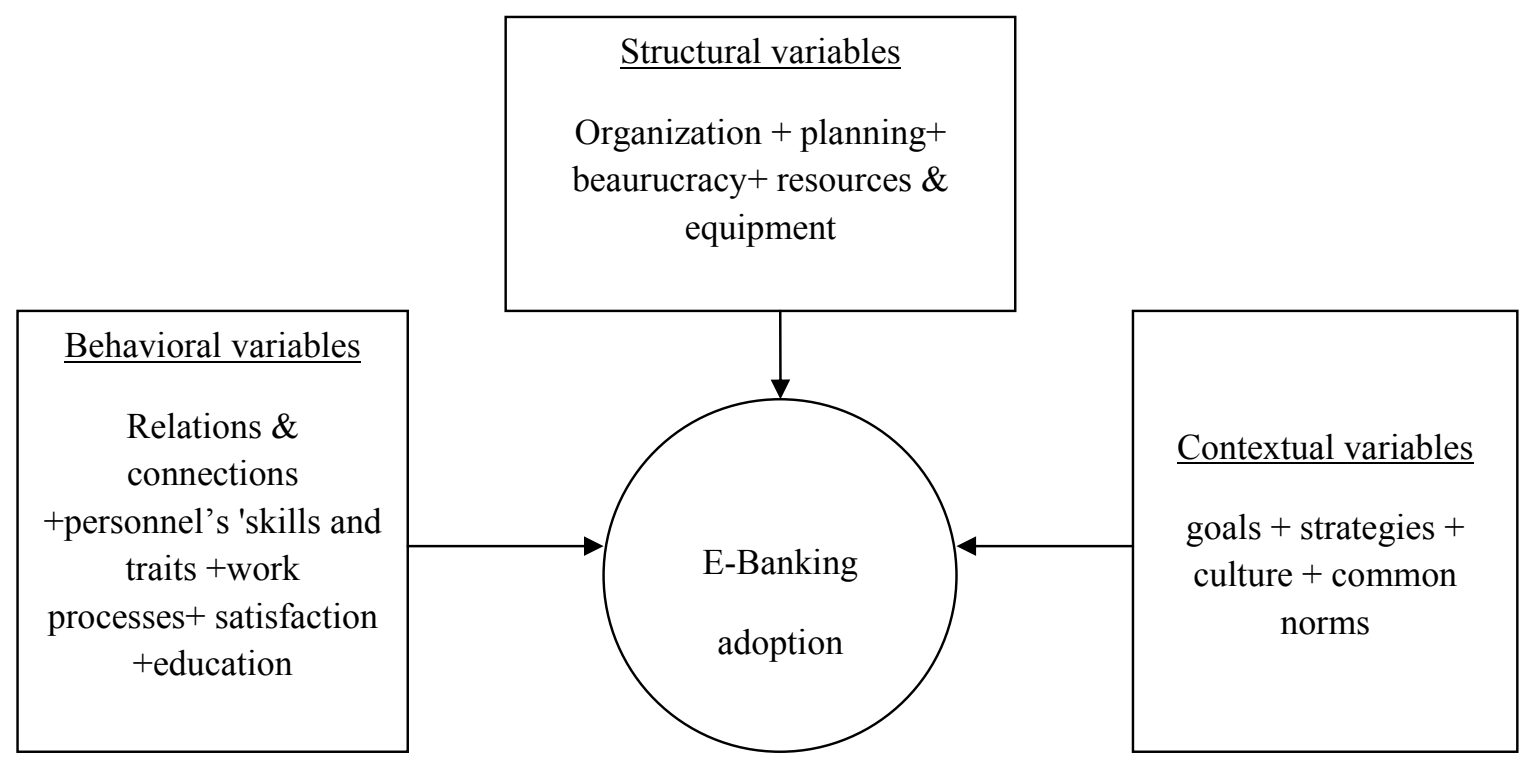

Fig. 1. The conceptual model of the adoption of E-banking

\subsection{Structural Variables}

In this category of variables are included both the product and service characteristics of the innovation, (Rogers, 1962; 1983; Rogers \& Shoemaker, 1971; Robertson, 1971), as well as the firm's internal technological environment. Most writers in marketing are keenly interested in the relationship between structural factors and the adoption of innovations and state that these factors generally put pressure on the company at every level. This pressure becomes particularly great when changes are introduced within the organization.

Risk tolerance refers to the level of uncertainty that decision makers can tolerate when introducing organizational change like the adoption of new electronic distribution and communication channels. It's a multidimensional construct (Bauer, 1960) composed of five distinct dimensions: tolerance to financial risk, performance risk, psychological risk, physical risk and social risk (Cox,1967; Jacoby \& 
Kaplan, 1972). For many specialists, perceived risk is a key factor determining the behavior visa-vis the adoption of innovations (Arndt, 1967; Ostiuncl, 1969; Shandh, 1968). Thus, the rapid adoption of an innovation would be attributable to, among other things, low perceived risk or high tolerance to risk (Gatignon \& Robertson, 1985; Webster, 1969). More specifically, some authors point out that security and confidentiality risks on the internet are serious barriers to the adoption of e-commerce (Bhimani, 1996; Cockburn \& Wilson, 1996; Quelch \& Klein, 1996).

Miller (1985) analyzed the impact of the technological environment on the adoption behavior of technological innovations by organizations. He stated that the more the firm has innovative manufacturing technologies, the higher is the probability of adopting other innovations. In essence, this means that the more the firm is used to adopting technologies, the greater its propensity to adopt more. This is a form of organizational innovativeness (Hirschman, 1980). With respect to the adoption of E-banking, we believe that the propensity of adopting new distribution channels would therefore be greater if the bank is used to introducing new information and communication technology as part of its business.

Rogers (1983) posited that the perceived relative advantage of an innovation is positively related to its level of adoption. In studying the factors influencing the adoption of Internet banking, Tan and Tao (2000) have shown that the perceived relative advantage of E-banking is positively related to its level of adoption by consumers. Webster (1969) mentions that the firms that are likely to adopt the innovations more quickly than the others are those who perceive the greatest relative advantage from the innovation. Based on these assertions, we think that the degree of adoption of E-banking is higher if the bank believes that this innovation might enhance its image, improve its efficiency and operational effectiveness, and increase its performance, in terms of market share, customer satisfaction, and costs.

$\mathrm{H}_{1}$ : There is a meaningful relationship between the structural factors and e-banking adoption.

\subsection{Behavioral variables}

Langley and Truax (1994) state that the presence of qualified staff members in the company having appropriate expertise in new information and communication technologies facilitates for banks the choice of these technologies and speeds up their adoption. Dixon and Nixon (2000) point out that financial institutions must have the internal resources, technical qualifications, and control of the technology in order to be able to adopt the Internet as a new distribution channel of products and services. Therefore, a bank with a high number of technically and scientifically skilled personnel will be more able to deal with risk and uncertainty brought on by the adoption of E-banking, and more likely to ultimately adopt the new technology.

Langley and Truax (1994) also emphasize that the possession of funds is a key factor when companies introduce technology. The adoption of E-banking technology, with its high costs, requires serious financial justification, not only to cover the costs of introducing the new technology, but also for learning about the new management model, technology support, application of new procedures, and the training of existing staff members. Thus, organizations which have greater financial resources and/or which have easier access to capital are more likely to introduce new electronic distribution and communication channels.

Previous studies have shown that substantially complex innovations require greater technical and operational abilities and effort in order to increase their chance of being adopted (Cooper \& Zmud, 1990 ; Dickerson \& Gentry, 1983). On the organizational level, Gauvin and Sinha (1991) indicated that the complexity of an innovation is associated with the concept of Inertia, in fact, the more the innovation is complex, the more the decision about its introduction within the organization is important. As E-banking increases in complexity, its adoption requires major changes within the bank, in terms of management and operations processes. This is recast as the following hypothesis: 
$\mathrm{H}_{2}$ : There is a meaningful relationship between the behavioral factors and e-banking adoption .

\subsection{Contextual Variables}

One of the critical decisions that a firm must make as it internationalizes its operations is the type of presence that it will have on the foreign markets (see, for e.g., Calof $\&$ Beamish, 1995). The different modes include licensing or franchise agreements, indirect or direct exporting, sales branches, joint ventures or wholly owned subsidiaries (Calof \& Beamish, 1995; Cho \& Padmanabhan, 1995).

In fact, the international environment in which the bank finds itself offers a wide opportunity to learn and to evaluate the importance of technological innovations and stimulates the adoption of Ebanking. The international presence allows the company to follow the tendencies of its competitive environment, to better serve customers in its global markets and to be informed in a continuous way. Possessing the right information at the right time constitutes an undeniable key of success in an international market.

Based on these arguments, we present the following hypothesis:

$\mathrm{H}_{3}$ : There is a meaningful relationship between the contextual factors and e-banking adoption.

\section{Methodology}

Mohr (1982) suggested that two fundamental types of theoretical approaches can be used to investigate organizational phenomena: "process" and "variance" models. While process models aim to understand the sequence of events leading to some result overtime, variance models focus on correlations between groups of variables and a specific outcome. In this study, we will be following the latter approach. Confirmative and convergence, variance analysis and the structural equations model which used in LISREL ,SPSS software packages are applied in this research.

\subsection{Sampling and data collection}

One of the most important stages of research is data gathering. We can gather the required data for the research in different ways. There are different tool for data gathering like observation, interview, questionnaire, documents, etc. Each of these tools has its own advantages and disadvantages.

Reliability is one of the technical characteristic of measuring tool. This concept is related to how much measuring tool in similar situations gives a similar result. Sarmad (2006) defined it as follows: "correlation between two series of goals in equivalent exams which is gained separately from examining group. With considering this aspect, typically range of efficiency of reliability is between zero (without relation) to one (full relation).this relation shows that how much measuring tool measures stable or variant and Temporary Examining Characteristic" . Cronbach alpha (Cronbach, 1951) was used and the results for our sampling was 0.9463 , which is well above the minimum desired level.

\subsection{Structural Equations Model}

In the recent decade, a lot of attempt had been made to examine causal relationship between variables in massive way. One of the hopeful methods in this area is structural equations model or multivariable analysis with latent variables.

\subsection{Definition of structural equations model}

Structural equations model is a comprehensive statistical approach for examine hypothesis about relations between observed variables and latent variables. Through this approach we can examine 
acceptability of theoretical model in special population by using correlation, experimental and nonexperimental data.

\subsection{Description of the Sample}

One of the most important factors which plays an important role to achieve the goal is the research's boundary.

To do the research essentially, we need to limit its content and its timing.

1) content-based boundary

This research concerning e-banking acceptance by financial institutes includes the structural, behavioral etc., which could be divided in to several sub-categories.

2) location-based boundary : Qazvin province's Mellat Bank's subsidiaries and head quarter offices

3) Time-based boundary:

This research has started since 2010 summer.The head quarter office's employees and the personnel of Qazvin province's Mellat Bank subsidiaries includes 300 people. Therefore we could use the following formula to calculate the minimum number of sample size,

$$
n=\frac{N \times z_{\alpha / 2}^{2} \times p \times q}{\varepsilon^{2} \times(N-1)+z_{\alpha / 2}^{2} \times p \times q},
$$

where $N$ is the population size, $p=1-q$ represents the yes/no categories, $z_{\alpha / 2}$ is CDF of normal distribution and finally $\varepsilon$ is the error term. Since we have $p=0.5, z_{\alpha / 2}=1.96$ and $N=300$, the number of sample size is calculated as $n=73$.

\section{Results}

\subsection{Descriptive statistics}

We have used LISREL software and the results of our survey have been summarized in Fig. 2 and Fig. 3. GFI $=0.91$, AGFI $=0.89$, RMSEA $=0.017<0.05$ rate shows suitability of structural model factor. In other words, observation data's to a large extent coincide with conceptual model of research. Resulted outcome from LISREL software confirm analysis results of SPSS software, as it is clear in software output figures, in resulted outcome of LISREL contextual factor with grade 1 has the highest effect on Electronic Banking Adoption, and behavioral and structural factors with $68 \%$ and $99 \%$ possessed other grades.

\subsection{Test of Hypotheses}

At the beginning of process, questionnaire distributed between statistical samples (Mellat-Bank employees-Qazvin province) and all of them returned questionnaires and after delivery of questionnaire by statistical population, primary examination performed them and we observed that all of questionnaire could be used for analysis and using in this research without any problem. Then in order to explain gained result from questionnaire, credit determination and currency questions performed and questionnaires answers grading and at the end total grade of questionnaire calculated. In this part, data's which are related to each research's questions and other required data are shown as frequency table. 


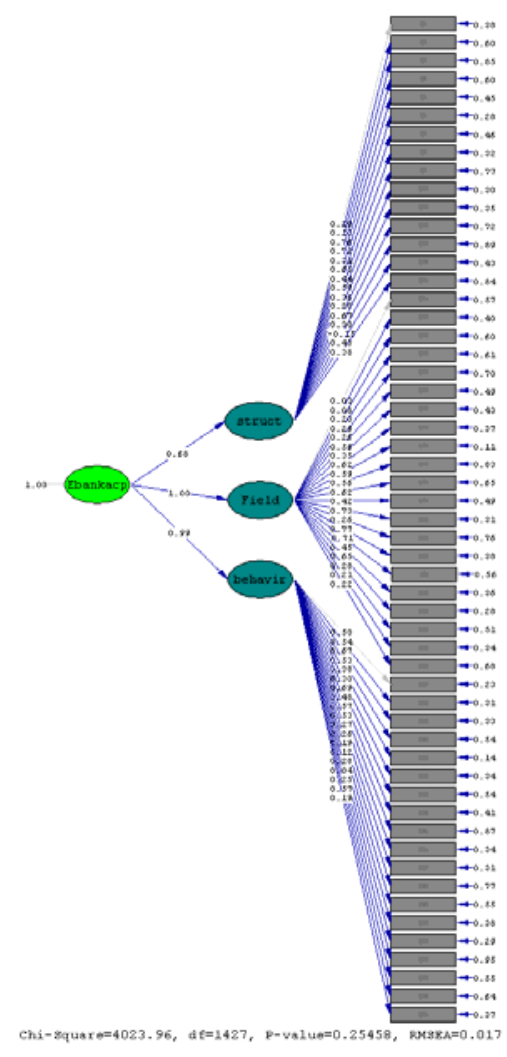

Fig. 2. LISREL results for the relationship between variables and the degree of adoption of E-banking

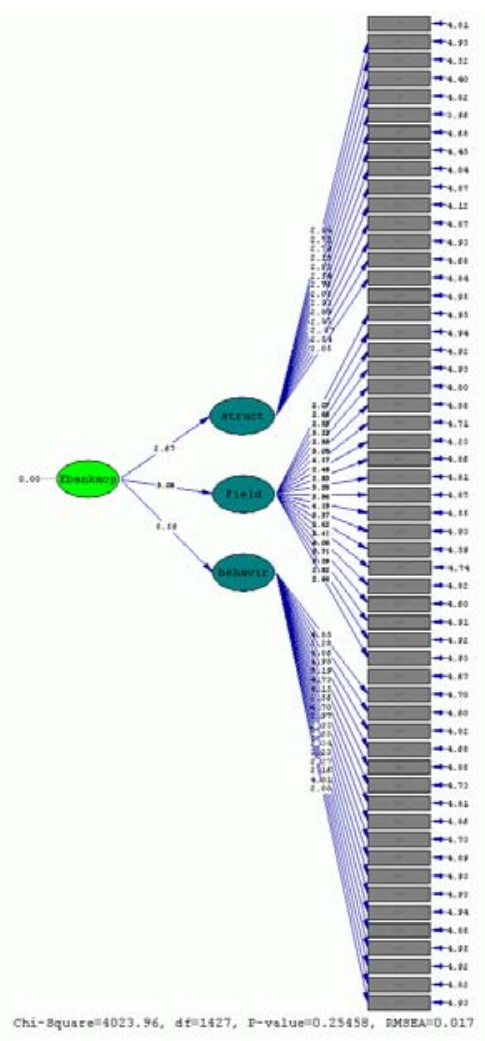

Fig. 3. LISREL results for the relationship between variables and the degree of adoption of E-banking

\subsection{Inferential Statistics}

It is used from inferential statistic techniques in this part. And for analyzing techniques of research is used from Chi-square exam.

First Hypothesis: There is a significant relation between structural factors and adoption of Electronic Banking.

$\mathrm{H}_{0}: \rho+0$

$\mathrm{H}_{1}: \rho=0$

\section{Table 1}

Shows Kai Square exam for adoption of Electronic Banking from structural factors view

\begin{tabular}{llllll}
\hline Name Of Variable & Variance & Standard Deviation & $\chi^{2}$ & df & Sig \\
\hline Appraisal of Structural variable & 3.356 & 0.439 & \multirow{2}{*}{29.778} & \multirow{2}{*}{13} & \multirow{2}{*}{0.005} \\
Electronic Banking Adoption & 3.478 & 0.385 & & & \\
\hline
\end{tabular}

Result of hypothesis 1: with regarding to above table, as it is observed that calculated Chi Square is significant (value of Sig in significant level model is less than 0.05). It means statistical hypothesis has been accepted with $95 \%$ assurance and zero hypotheses rejected. In the other words, there is a significant relation between structural factors and Electronic Banking adoption.

Second Hypothesis: There is a significant relation between behavioral factors and Electronic Banking Adoption. 
$\mathrm{H}_{0}: \rho \neq 0$

$\mathrm{H}_{1}: \rho=0$

\section{Table 2}

Shows Kai Square exam for adoption of Electronic Banking from behavioral factors view

\begin{tabular}{llllll}
\hline Name Of Variable & Variance & Standard Deviation & $\chi^{2}$ & df & Sig \\
\hline Appraisal of behavioral factors & 3.580 & 0.418 & \multirow{2}{*}{0.978} & \multirow{2}{*}{15} & \multirow{2}{*}{0.029} \\
Electronic Banking Adoption & 3.478 & 0.358 & & & \\
\hline
\end{tabular}

Result of hypothesis 2: with regarding to above table, as it is observed that calculated Chi Square is significant (value of Sig in significant level model is less than 0.05). It means statistical hypothesis has been accepted with $95 \%$ assurance and zero hypotheses rejected.

Third Hypothesis: 3-there is a significant relation between Behavioral factors and Electronic Banking Adoption.

$\mathrm{H}_{0}: \rho \neq 0$

$\mathrm{H}_{1}: \rho=0$

Table 3

Shows Kai Square exam for adoption of Electronic Banking from contextual factors view

\begin{tabular}{llllll}
\hline Name Of Variable & Variance & Standard Deviation & $\chi^{2}$ & df & Sig \\
\hline Appraisal of contextual factors & 3.473 & 0.429 & \multirow{2}{*}{25.556} & \multirow{2}{*}{15} & \multirow{2}{*}{0.043} \\
Electronic Banking Adoption & 3.478 & 0.385 & & & \\
\hline
\end{tabular}

Result of hypothesis 3: with regarding to above table, as it is seen, calculated Chi Square is significant (value of Sig in significant level model is less than 0.05). It means statistical hypothesis has been accepted with $95 \%$ assurance and zero hypotheses rejected. In the other words we can conclude that there is a significant relation between contextual factors and Electronic Banking adoption.

\subsection{Admission ability of research model factors regarding to structural factor questions}

In this analysis, researchers try to consider the model using $\chi^{2}$ track analysis and other criteria. If $\chi^{2}$ test is less than the determined and expected anticipation, it will be better because this can be accounted for the difference existing between data and model . It needs to be mentioned that GFI test and AGFI must be more than 90 percent (Hooman, 2008).

\section{Table 4}

SPSS results for the ranking of variables based on points acquired

\begin{tabular}{|c|c|c|c|c|c|c|}
\hline Dimensions of managerial & Score & Average & Variable & Score & Average & Rank \\
\hline \multirow{4}{*}{ structural } & \multirow{4}{*}{4531} & \multirow{4}{*}{3.356} & organization & 1491 & 3.313 & 4 \\
\hline & & & planning & 994 & 3.681 & 11 \\
\hline & & & equipment & 1145 & 3.180 & 8 \\
\hline & & & Resources synergy & 901 & 3.337 & 13 \\
\hline \multirow{4}{*}{ Contextual } & \multirow{4}{*}{6565} & \multirow{4}{*}{3.473} & goals & 1413 & 3.140 & 6 \\
\hline & & & strategies & 1528 & 3.395 & 3 \\
\hline & & & culture & 1486 & 3.302 & 5 \\
\hline & & & Common values & 2138 & 3.959 & 1 \\
\hline \multirow{5}{*}{ Behavioral } & & & relationship & 1325 & 3.680 & 7 \\
\hline & & & Skills, personels personality & 1716 & 3.813 & 2 \\
\hline & 6122 & 3.580 & Banking work process & 1107 & 3.075 & 9 \\
\hline & & & satisfaction & 1068 & 3.955 & 10 \\
\hline & & & education & 906 & 3.355 & 12 \\
\hline
\end{tabular}


Therefore, it will be better if the amount of RMSR test is less because of being a criterion for the average difference between the observed data and the model data (Hooman, 2008). The results show that the model is appropriate. In accordance with the LISREL output, the amount of $\chi^{2}$ equals 4023.96 ( if the amount of $\chi^{2}$ in proportion to $\mathrm{df}$ is less than 3 , the amount of would be adequate as well as the model adequacy, this measurement is 2.87 in this research.

If the difference existing between the conceptual model and the observed data is calculated less than the expectation, this indicator will be less. The results show that the amount of RMSEA is 0.017 , if the amount of RMSEA is more less, the model will be more appropriate. The measurement model shows the influence of each variant of 15 questions, $3^{\text {rd }}$ question which was calculated $64 \%$ (Fig. 2), $4^{\text {th }}$ question which was measured $68 \%, 6^{\text {th }}$ question which was calculated $78 \%, 8^{\text {th }}$ question which was calculated $66 \%$ and $17^{\text {th }}$ question calculated $78 \%$ are more appropriate than others, so they can explain the structural factor variance well. The meaningful part of coefficient and the resultant parameters shows that all coefficients would be meaningful and significant. This can be explained by being more than 2 and less than -2 . These numbers are meaningful by which we can conclude that the model can be confirmed because of its meaningfulness.

\subsection{Admission ability of research model factors regarding to contextual factor questions}

In contextual factor, question 24 with $78 \%$, question 28 with $79 \%$, questions 30 and 32 with $78 \%$ were able to describe contextual factors variance better than the others. Results of ratios significant section and achieved parameters shows that all of the achieved ratios were significant, because significance exam value of each of them is greater than 2 and less than -2 (figure 3). Significance of these numbers shows significance and confirmation of model. In other words, placing each of answers in form of each 3 fold worked out factors model is significant.

\subsection{Admission ability of research model factors regarding to behavioral factor questions}

In behavioral factors, questions 37 with $72 \%$, question 38 with $70 \%$, question 41 with $72 \%$ were able to describe behavioral factors variance better than others. Significance of numbers which relates to $t$ exam shows significant and confirmation of model. In other words, placing each of answers in form of each 3 fold worked out factors model is significant.

\subsection{Discussion}

In this section researchers intended to present suggestion and solutions for better use of Structural, Behavioral and Contextual Factors for their effect on Electronic Banking Adoption in financial institutions with research results.

Regarding to performed analysis in contextual factors section. Organization goals and programs, especially in Electronic Banking, continually documented and describe for employees completely in order to action direction of organization be clear and distinctive, and goals make employees to be dynamic and their endeavors for organizational goals. In order to units be knowledgeable about environmental conditions and its changes, Organization environmental changes and technology progress continually observes and as it is possible, inform to different units and employees. Employees' knowledge about competitor conditions and their environment increase their motivation for competition, increase their preferences, and make more endeavors for achieving to modern services goal. We must provide some solutions for making sympathy between employees and cooperation culture in order to through it we can use these solutions as a strategy for organizations progress. We need to use team work for improving efficiency, in order to with cooperation of organization personnel's move toward goals, so it is suggested to support from team work. 
Regarding to performed analysis in behavioral factors section, it is suggested that encouragement and persuasion must be increased in employees in order to as a competition privilege, cause organizations preference upon competitors. Employee's suggestion process with reward motivation cause optimum solutions for cost management and increasing of efficiency. Revision of employee's occupational process must be emphasized for modern services, in order to with some changes make better occupational conditions for their duty performance. Education of employees, especially in Electronic Banking, must be organized in order to employees gain proper qualification and justified for optimum duty performance. Educational classes must be presented for employees' familiarity with modern services functioning method.

Regarding to performed analysis in structural factors section, methods and surfaces of achieving to banking modern services must be distinct to avoid from confusion of middle managers, executives and organizations employees. The path of progress must be distinct and clear for employees, in order to avoid from discouragement and hope for occupational progress make a motivation for them. Job description must be codified and distinct job instruction must be prepared for employees in order to avoid from job interference and hypo function, because of lack of job justification in some of employees. In order to achieving to banking modern services, preparation of resources and facilities is necessary and organization must provide necessary tools with investment and research.

\section{Conclusion}

In this paper, we have examined contextual, structural and organizational factors, which could facilitate or slow down adoption of innovation in Electronic Banking in the financial Institutions. Three-dimensional model co-structure, co-behavioral, contextual (3C) is used in this research. This schema was a logical model in the categories of models and many of concepts, events and organizational phenomena could be examined. Structural factors including type of the organization of institution, work distribution, preparing mobilization of resources and equipment and risk of decisionmaking sophistication influence on adoption of Electronic Banking. We hope the proposed model and suggestions could facilitate the adoption of electronic banking.

\section{References}

Agarwal, R., Rastogi, S., \& Mehrotra, A. (2009). Customers' perspectives regarding e- banking in an emerging economy. Journal of Retailing and Consumer Services, 16, 340-351.

Almogbil, A. (2005). Security, perceptions, and practices: challenges facing adoption of online banking in Saudi. Unpublished Ph.D. Thesis, George Washington University, Washington.

Ajzen, I. (1985). From intentions to actions: A theory of planned behavior. In J. Kuhl, \& J. Beckmann (Eds.), Springer series in social psychology (pp. 11-39). Berlin: Springer.

Aladwani A.M. (2001). Online banking: A contextual study of drivers, development challenges and expectations. International Journal of Information Managements, 21(3), 213-225.

Arndt, J. (1967). Role of product- related conversation in the diffusion of a new product. Journal of Marketing Research. 4. 291-295.

BankData(2004). Bilanbanques. Beirut, Lebanon.

Bauer, R.A. (1960). Consumer Behaviour as Risk Taking. In R.S. Hancock (ed), Dynamic Marketing for a Changing World. Chicago. American Marketing Association.

Bergeron, J. (2001). Les facteurs qui influencent la fidelite des clients qui achetcnt sur Internet [The factors influencing the loyalty of online purchasers). Recherche et Applications en Marketing, 16(3), 39-53.

Bhimani. A. (1996). Securing the commercial Internet. Communications of the ACM. 39 (6). 29-35.

Bradley, L. \& Stewart K. (2002). A Delphi study of drivers and inhibitors of internet banking. International Journal of Bank Marketing, 20(6), 250-260.

Bughin, J. (2003). The diffusion of Internet banking in western Europe. Electronic Markets. 13(3). 251-258.

Calof, J. L. \& Beamish P.W. (1995). Adapting to foreign markets: Explaining internationalization. International Business Review. 4(2). 15-31

Christensen, C.M. \& Raynor MJE. (2003). Innovator's Solution: creating and sustaining successful growth. Harvard Business School Press, pp. 303. 
Churchill. G.A. (1979). A paradigm for developing better measures of marketing constructs. Journal of Marketing Research, 16. 64-73.

Cho, K.R. \& Padmanabhan, P. (1995). Acquisition versus new venture: The choice of foreign establishment mode by Japanese firms. Journal of International Management, 1(3). 255-85.

Cockburn. C. \& Wilson. T.D. (1996). Business Use of the World-Wide Web. International Journal of Information Management, 16(2). 83-102.

Cooper R. B. \& Zmud, R. W. (1990). Information technology implementation research: a technological diffusion approach. Management Science, 36(2), 123-139.

Cox. D.F. (1967). Risk taking and information handling in consumer behaviour. Harvard University press.

Cyr, D., Bonanni, C., Bowes, J., \& Ilsever, J. (2005). Beyond Trust: Website Design Preferences Across Cultures. Journal of Global Information Management, 13(4), 24-52.

Cronbach, L. J. (1951). Coefficient alpha and the internal structure of tests. Psychometrika, 16(3), 297-334.

Dabholkar, P.A. (1996). Consumer evaluations of new technology- based self service options: an investigation of alternative models of service quality. International Journal of Research in Marketing, 13, 29-51.

Daniel. E. (1999), Provision of electronic banking in the UK and the Republic of Ireland. International Journal of Bank Marketing. 17(2), 72-82.

Deisc, M. V., Nowikow, C, King. P. \& Wright, A. (2000). Executive s Guide to E-business: From Tactics to Strategy. Price water house coopers L.L.P., 272.

Damanpour. F. (1987). The adoption of technological, administrative, and ancillary innovations: Impact of organizational factors. Journal of Management, 13, 675-688.

Davis, F.D. (1989). Perceived usefulness, perceived ease of use. and user acceptance of computer technology. MIS Quarterly, 13(3), 319-340.

Dicherson M. D. \& Gentry J. W. (1983). Characteristics of adopters and non-adopters of home computers. Journal of Consumer Research, 10(2), 225-235.

Ernst and Young (2001). Global Online Retailing. An Ernst and Young Special Report, pp.142.

Fishbein, M. \& Ajzen. I. (1973). Belief. Attitude, intention, and Behavior: An Introduction to Theory and Research. Addison-Wesley. Reading. MA.

Furst. K.. Lang., W.W., \& Nolle. D.E. (2002). Internet Banking. Journal of Financial Services Research, 22(1,2), 95-117.

Gatignon, H. \& Robertson, T. S. (1985). A proposal inventory for new diffusion research. Journal of Consumer Research, 1, 249-267.

Gauvin. S. \& Sinha. R. (1991). Innovativeness In industrial Organisations: A two-Stage Model of Adoption. Working paper. University of Laval. Canada.

Gourville, J.T. (2003). Why consumers don't buy: the psychology of new product adoption. Harvard Business School Publishing.

Hartwick, J., \& Barki, H. (1994). Explaining the role of user participation in information system use. Management Science, 40 (A), 440-465

Hernandez, J.M.C. \& Mazzon J. A. (2007). Adoption of Internet banking: proposition and implementation ofan integrated methodology approach. International Journal of Bank Marketing. 25(2), 72-88.

Ilirchman, E. C. (1980). Innovativeness, Novelty Seeking and consumer creativity. Journal of Consumer Research, 7. 283-295.

Im, I., Kim, Y., Han, H. J. (2008). The effects of perceived risk and technology type on users' acceptance of technologies. Information \& Management, 45, 1-9.

Infopro (2003). The Business Handbook. Beirut. Lebanon.

Jacoby, J. \& Kaplan. L. (1972). The components of perceived risk . Advances in Consumer Research. ed. Venkalesan M.. Association for Consumer Research, 287-291.

Karjaluoto, H., Mallita. M. \& Pento T. (2002). Factors underlying attitude formation towards online banking in Finland, International Journal of Bank Marketing, 20(6), 261-272.

Kimbcrly. J.R., \& Evanisko, M.J. (1981).Organization innovation: the influence of individual, organizational, and contextual factors on hospital adoption of technological and administrate $\backslash$ innovations. Academy of Management Journal. 24(4). 689-713.

Kirsner. I. \& Balbi. D. (1997). Les besoins des banqucs. Banque. 586. 38-39.

Kolodinsky. J.M.. Hogarth. J.M. et Hilgert. M.A. (2004). The adoption of electronic banking technologies by US consumers. International Journal of Bank Marketing. 22(4/5). 238-259. 
Kotler, P. (1991). Marketing Management: Analysis. Planning. Implementation and Control. Prentice-1 lull International Inc.. Lnglewood Cliffs, New Jersey. 7th edition.

Kuisma T., Laukkanen T., \& Hiltunen M. (2007). Mapping the reasons for resistance to Internet banking: A means-end approach, International Journal of Information Management, 27, 75-85.

LeBlanc R. (2006). Attention: virage electronique en cours. Postes et la societe del'information, 20-23

Langley. A. \& Truax J. (1994). A Process Study of new Technology Adoption In Smaller Manufacturing firms. Press of University of Quebec in Montreal.

Lee, E., Lee, J. \& Eastwood, I. (2003). A two-step estimation of consumer adoption of technology-based service innovations. Journal of Consumer Affairs. 37 (2), 256-282.

Miller. A. (1985).Technological thinking: Its impact on environmental management. Environmental Management. 9(3), 179-190

Mohr, L.B. (1982). Explaining Organizational Behaviour. San Francisco: Jossey-Bass

Mots. N. P. (1998). The behavioral consequences of PC banking. International journal of bank marketing. $16(5), 195-201$.

Munos, A. (1999). Technologies \& Metier de service [Technologies and service professions]. Decisions Marketing, 17, 55-65.

Nunnally. J.C. (1978). Psychometric Theory. New-York: McGraw-Hill.

Ostlund. L. E.(1969). The role of Product Perceptions in innovative behaviour, in ed. P.R. Mac Donald. Marketing Involvement in Society and the Economy. Chicago: American Marketing Association , 259-266.

Perrien. J., Filiatrault. P., \& Richard, L. (1993). The implementation of relationship marketing in commercial banking. Industrial Marketing Management, 22.141-148.

Pikkarainen, T., Pikkarainen, K., Karjaluoto, H., \& Pahnila, S.(2004). Consumer acceptance of online banking: an extension of the technology acceptance model. Internet Research, 14(3), 224-235

Quelch, J.A. \& Klein. L.R. (1996). The Internet and International Marketing, Sloan Management Review. Spring, 60 - 75 .

Raju, P.S. (1980), Optimum stimulus level: its relationship to personality, demographics, and exploratory behavior. Journal of Consumer Research, 7, 272-282.

Rieard L. \& Perrien .1. (1999). Explaining and evaluating the implementation of organizational relationship marketing in the banking industry: Client's perceptions. Journal of Business Research, 45. 199- 209.

Rogers, E. M. (1983). Diffusion of innovations. New York: The free press

Rogers, E. M. \& Shoemaker, F.F. (1971), Communications of Innovations. New York. Free Press.

Robertson, T. S. (1971). Innovative Behaviour and Communication. New York. Holt, Rinehart and Winston.

Rust, R.T. \& Kantian. P.K. (2002). E-Service: New Directions in Theory and Practice. ME Sharpe. Artnonk, New York. NY.

Sathye. M. (1999). Adoption of Internet banking by Australian consumers: an empirical investigation. International Journal of Bank Marketing. 17(7). 324 - 334.

Sayar, C. \& Wolfe. S. (2007). Internet banking market performance: Turkey versus the UK. International Journal of Bank Marketing. 25(3). 122-141.

Shandh, J. N. (1968), A factor analytic model of brand loyalty. Journal of Marketing Research. 5, 395 -404.

Tan, M. \& Teo, T. S.H. (2000). Factors Influencing the Adoption of Internet Banking. Journal if the Association for Information Systems, 1(5). 1-44.

Venkatesh, V., Morris, M.G., Davis, G.B. \& Davis F.D. (2003). User acceptance o fin formation technology: Toward a unified view, MIS Quarterly. 27(2), 425-478.

Venkatraman. N. (1995). Reconfigurations d'entreprises provoquees par les technologies de Finformation, in L'entreprise competitive aufutur, Ees Editions d'Organisation, 151-195

Villates,D.( 1997).Demain, labanqueadistance [The Distant bank of tomorrow] Banque. 585, 68-70.

Wah, L.. (1999). Banking on the Internet. American Management Association, 88 (II). 44-48.

Walsh. S.T., Kirchhoff. B.A. \& Newbert, S. (2002). Differentiating Market Strategies for Disruptive Technologies. IEEE Transactions on Engineering Management, 49, 341-351.

Webster. F.E.J. (1969). New Product Adoption in Industrial Markets: A Framework for Analysis, Journal of Marketing Research, 33(3), 35-39. 